\title{
Evaluating different types of signs in Reuters photos from the Peirce and Burgin's perspectives
}

\author{
Foroogh Kazemi
}

\author{
Assistant Professor of Linguistics, Central Tehran Branch. Islamic Azad University, Tehran, Iran. \\ Email: f.kazemi86@yahoo.com \\ Narjes Ghasemi Ateni \\ M. A Student of Linguistics, Central Tehran Branch. Islamic Azad University, Tehran, Iran. \\ Email:narges.ghasemi.63@gmail.com
}

\begin{abstract}
This article sought to comparatively examine different types of signs in Reuters news agency photos from Peirce and Burgin's perspectives. The research data are photos with social and cultural themes being selected from the Reuters news agency which depicted the Iranian customs, traditions and culture. The research is accomplished focusing on a variety of signs from Peirce and Burgin's perspectives. This study attempted to answer these questions that "In Reuters social photos which sign has the highest frequency?", "Can semiotic theories be applied for photo interpretation?" and "does the semiotics study of Reuters social photos lead to the fact that photography has an arbitrary system?" The findings showed that 14 photos were consistent in terms of Burgin and Peirce's perspectives, but for 16 photos, these two views were incompatible with each other. According to the fact that the data analyzed in this study were photos, all photos had an iconic relationship with their object (theme).Therefore, the iconic signs were 30 enjoying the highest frequency. The indexical signs had a frequency of 14 and the last belonged to symbolic signs with 10 cases. The findings also suggested that semiotic theories can be applied in photos interpretation. In addition, the semiotics in Reuters social photos made it clear that photography has an arbitrary system.
\end{abstract}

\section{Keywords: semiotics, signs types, news media, photos. INTRODUCTION}

Semiotics is the study of sign systems covering human social life. Charles Sanders Peirce, an American philosopher, introduced his theory of signs as semiotics. His theory focused on the signs logical functions. He put emphasis on the signifier as the field of semiotics covers the study of all signifier systems. Since 1950s, the art history has repeatedly lost semiotics and regained it again and writers now employ a variety of combination which are essentially derived from de Saussure and Pierce. Perhaps the Peircean model (1914-1839) was the most influential model but Saussurean model (1913-1857) in 1970, during the post-structuralism era, is more convergence with the history of art. Currently, the photo semiotics as a similar approach in text analysis can bring us to the scope of photos meaning. A sign is a symbol to express or understand a concept and semiotics also explores different types of signs and factors present in creating and interpreting process and deals with rules governing signs. In other words, semiotics is the sign cognition science and aims at understanding rules that create a concept and meaning. At present, human life is surrounded by a variety of visual cues making human inevitable in their reading. We cannot remember a day being spent without seeing and reading these photos being exposed to us without our questioning. Therefore, this study aimed at finding an answer to these questions that in Reuters news agency social photos, "which signs have the highest frequency?"'"Can semiotic theories be applied for photo interpretation?" and "does the semiotics study of Reuters social photos lead to the fact that photography has an arbitrary system? ".Victor Burgin (1982), in his book "creative photography", considered spending a day without seeing a picture as so strange as if you spend a day without seeing a written text. Now that photos which talk to us like written texts and have penetrated deep in our lives, identifying and understanding the relationship among signs in photography and their corresponding social functions can cast light on many social phenomena and historical concepts, therefore, it is important to conduct such research. In this study, we used the library research for data collection including 30 photographs from Reuters news agencies with social themes which were collected using simple random sampling being conducted through descriptive - analytical approach.

\section{A review of the literature}

The ancient Greeks could be known as the first people who focused on semiotics. In ancient times, Plotinus believed that every work of art should offer an "idea". For example, an architect has an idea in mind and builds a house out of his mind. In his opinion, the work of art is a sign that refers to the world of ideas. Intellectual tradition through the realms of which non-verbal human communication such as gestures, facial expressions (gesturology), as well as ways of place interaction (interactionology) can be mentioned, is the field in which semioticians encounter with human behavior anthropologists ideas. Barthes (1977: 13) in an article, entitled meanings of visual expression, expressed a certain position for the photographic images which accounted for the unencrypted messages. Among all kinds of images, it is just the photos that have the ability to give all the information without having any difficulty in the interpretation. For this reason, he considered the photo message as a continuous message that is the result of a mechanical record, not a transfer between signifier and signified. Duboa (1983), by attributing meaning to an index, is considered as true Peircean orthodox. According to this view, each symbol is explained not only because of the actual contact between the surface expression, reference or content, but more than this, for the embodiment and representation of the principles that are called "Selection and uniqueness" features. 


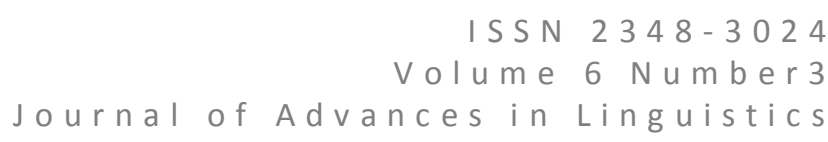

\section{Signs from Saussure and Peirce's perspective:}

The term "sign" and consequently different types of signs such as symbols was introduced to modern era scientific literature by Charles Sanders Peirce' tripartite division of signs, an American pragmatist philosopher, and was used in various sciences. In his broad definition, Peirce considers signs not anything other than logic. Signs reach the meaning through the abstraction of the mind and can always be different when considering the mind which is always faced with some kind of arbitrariness. "(Fokuhi, 2004: 301)

Contrary to Saussure, Peirce does not focus on a sign, but also he pays attention to the creation and interpretation process, referred to as Semiosis, setting it at the center of his semiotic theory. Semiosis requires three elements of sign, representation and interpretation. The Semiosis process associates the signs with their representations. In this process, signs are "something that sits in someone's mind as something ". Consequently, we can see that Peirce's semiotic theory is based on a trichotomy of the elements which cannot be reduced to Saussure' dichotomy. Peirce (1931) introduced the three-dimensional model:

- Representation: the structure that a sign has (and is not necessarily material.)

- Interpretant: not an interpreter, but the meaning achieved from a sign.

- Object (object): the sign is referred to.

\section{Different types of signs based on Peirce's perspective:}

\section{Iconic signs:}

It is based on the similarity relationship between signifier and signified, or a sign and the object. For example, photographs, cartoons and replica, phonemes, metaphor, real sounds in music and so much more can be used.

\section{Indexical signs}

They are based on a causal or physical relationship between the signifier and signified. This relationship is not arbitrary and is like a smoke which is the sign of fire or in languages such as personal pronouns, adverbs of time and place.

\section{Symbolic signs}

They are based on an abstract or arbitrary relationship with a dependent signified including linguistic signs, musical notes, Morse alphabet and others. Implications play an important role in symbolic signs. (Sojudi, 2008, 27)

\section{Burgin's perspective}

Victor Burgin (1982: 22), British artist and photographer, who is influenced by philosophers and theorists such as Karl Marx, Sigmund Freud, Jacques Derrida, Michel Foucault, Roland Barthes and Jacques Lacan, was involved in the field of art, especially photography. He is widely appreciated in art criticism and theory. In addition, a collection including his written essays, talks, scientific forums and a number of artistic theories that are arranged in chronological order, has been published in a book called "parallel Text". According to Burgin, theorizing in art initiated by the formation of interconnected art history and art criticism in the Enlightenment era reached its climax in the late modernism and ended in contemporary period. Thus, in spite of such a theory, he expressed his theories on art criticism; because any discussion on the art has a theorizing feature in nature. Hence, his theory can be considered as a kind of paradox because he is an artist who focuses on art criticism and theory. According to Burgin, the first Semiotician who emphasized the indexical nature of photography was Maldonado (1974). He shared some of the ideas with Duboa on theories which focus on photos verbal cues like other types of images and in this regard he believed that the photos can only be indexical and should be examined from this perspective. He believes that the discourse made by text photo relationship, and like other texts, they are linked with their discourse. Therefore, photos are not easy to make. The term conceptual art was coined for the first time by scientists such as Victor Burgin and Joseph Kastot, in 1967. Conceptualism is very similar to minimalism in terms of physical functioning. That's why critics such as Burgin are sometimes referred to as minimalist.

\section{Photos analysis from the semiotics perspective}

In this part of the study, six photos analysis out of 30 are presented. Then at the end of this section, results of the data analysis are presented in tables and graphs.

Photo 1

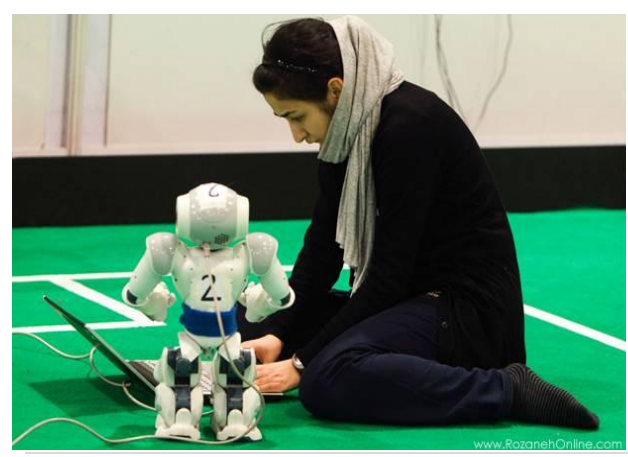

1058 | $\mathrm{P}$ a g e

April 2016 
This photo shows a very humble girl with no make-ups, which represents the traditional Iranian women, but her outfit does not resemble that of a traditional woman. In this image, she is doing something which has been considered a male occupation in the past, but today, according to new science field and research in science and new technologies, science is no longer a gender-related field exclusive to men. Here, the photographer ignores and overlooks the Iranian traditional culture. Also, in this picture, the photographer tried to point to this issue that taking advantage of the new Science and Technology (computer use) which can lead to the invention of robots is only possible with modern look and outfit. As a result, according to the Pierce's perspective (1931) and semio-semantics, there is an indexical relationship between signifier and signified, in which the robot is the signifier and the inventor is the signified. In addition to the indexical relationship, because of the similarities in the image and the object for each photo, the iconic relationship is also perceivable. According to the description provided, the indexical relationship in the photo fits the Victor Bergin's approach.

Photo 2

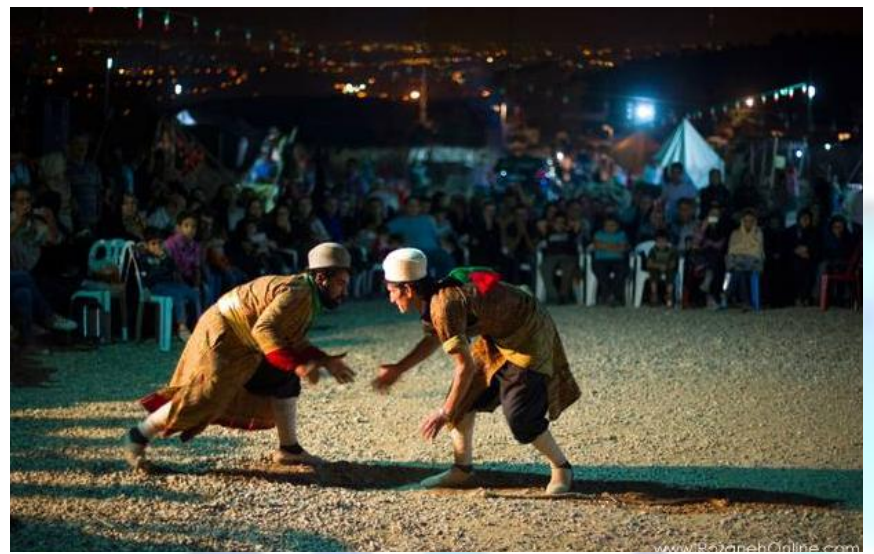

The image above shows two wrestlers who are wrestling, and there are a lot of people, men, women and children who are watching the competition. Today, due to the spread of urban culture in Iranian society, many national, local and ethnic customs and rituals have been disregarded, but by holding festivals and ritual the loss of ancient Iranian culture and traditions would be prevented. In this image, the photographer tried to portray some of the traditional Iranian culture and the way they are revived in Iranian society. Therefore, a causal relationship has been established in the picture and celebrating the cultural traditions by different ethnic groups preserves the ethnic customs and Iran's national society and it is a way to be familiar with Iranian ancient culture. Therefore, in accordance with the Pierce' views (1931) and in terms of semio-semantics, there is an indexical relationship established in this picture endorsing the Bergin's ideas because he believes that because of the existence of a causal (signifier/signified) relationship between signs and meaning, photos can only be indexical. In addition, because of the similarities in the image and the object for each photo, the iconic relationship is also used.

Photo 3

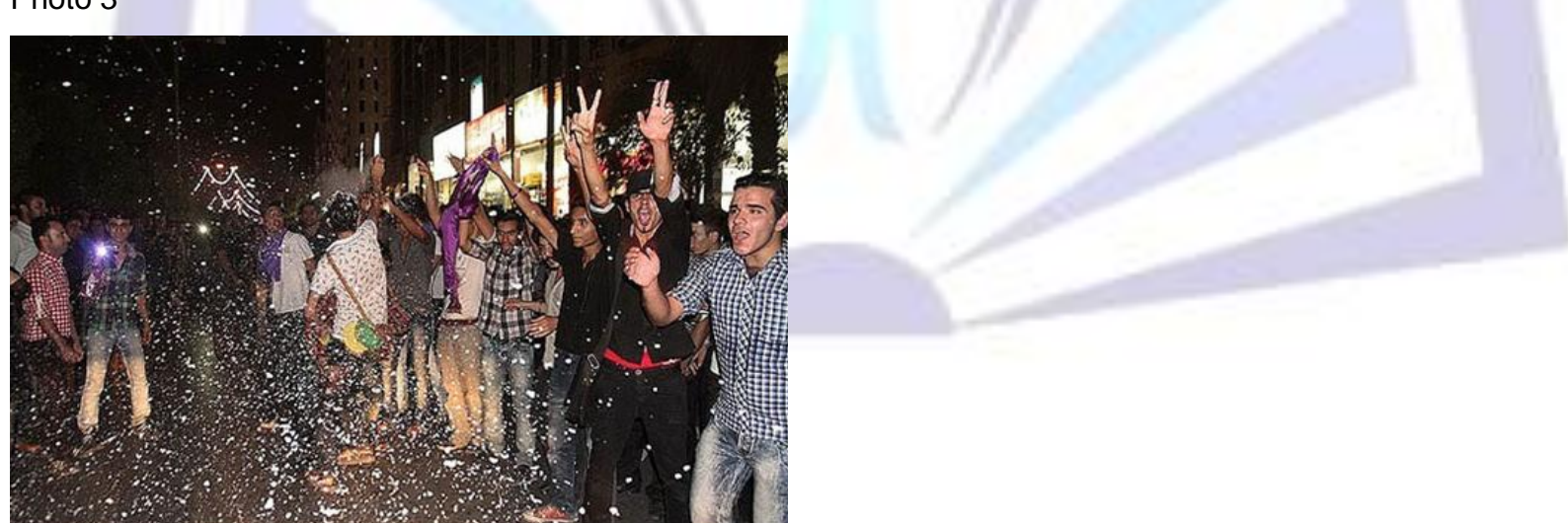

In this image, people's celebrations in the streets after the presidential election and Rohani's victory are portrayed. After the election results were announced, people gathered in the streets and celebrated their candidate's victory, all the people shown in the picture are men. Nowadays, women in Iran have an active role in the political matters, but in this picture there is no sign of the women in this political event. Perhaps the photographer in this picture wanted to point to the fact that the Iranian people are committed to their political parties and affiliations, but the Iranian political behavior among men is stronger than that of women. In this image, there is a causal relationship between signifier and signified. The celebration depicted in the image is a sign of victory. When a successful event occurs, consequently, people hold celebrations, Therefore, consistent with the Pierce' views on semio-semantics, there is an indexical relationship established in this picture, the victory is the signifier and celebration is the signified. Each photo has an iconic because of the similarity of sign and the object. There is an indexical relationship established in this picture endorsing the Bergin's ideas. 
Photo 4

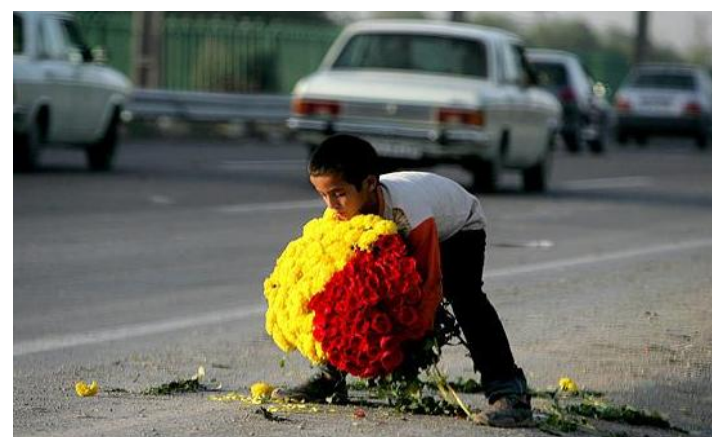

The picture depicts a child in the middle of the street with a large and heavy bouquet of flowers on his hand; seemingly some of the flowers fell on the ground. This photo has portrayed child labor in Iran. The Reuters photographer, referring to this counter-cultural phenomenon in Iran, is trying to make a mountain out of a molehill about the child labor in Iran and has been trying project this issue to attract the international attention on the problem in Iran. When we see children working on the streets, it raises some issues in society reflecting the lack of family support, inability of the family in coping family and children's expenses, lack of social welfare and poor cultural level, therefore, a causal relationship can be seen in the image understand in which the cause (signifier) is the children's work on the streets due to the lack of financial and social support of families and individuals in the community, and the effect (signified) is seeing the child labor in the street, so the signifier and signified relationship, along with Peirce's theory, is indexical and in terms of semio-semantics, a logical and casual relationship is established between signifier and signified. The indexical relationship in this photo is consistent with Victor Burgin's approach because he believes that the image, based on the semio-semantics prospective, can only be indexical and the signifier/ signified relationship is established between the Sign and meaning. Also, because of the similarities in the image and the object for each photo, the iconic relationship is also used.

\section{Photo 5}
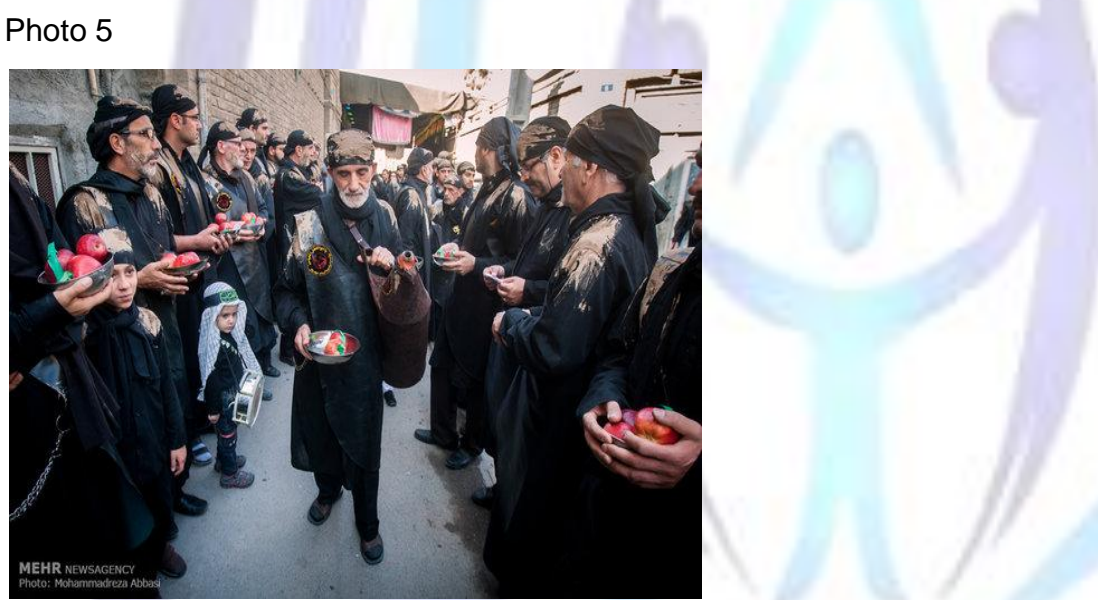

In this photo, we see a crowd of people in a traditional ritual of Ashura in Iran. All participants in the ceremony wearing similar black clothing and i all have rubbed some dirt and mud on their clothes, and have votive apples in their hands. In this photo, the photographer is trying to give the audience a familiarity with the customs and religious rituals in Iran. This image has portrayed a symbolic gesture of Iranians' mourning for Imam Hussein. Despite the fact that the special incident in Karbala was related to more than 14 centuries ago, Iranians still hold ceremonies and rituals for this tragic incident and wear black clothes. Therefore, from the Peirce's semio-semantics perspective, a symbolic relationship is established between the signifier and signified. The sign and the meaning do not match the Burgin's perspective that focuses on the indexical relationship in the photo. Also, because of the similarities in the image and the object for each photo, the iconic relationship is also used.

\section{Photo 6}

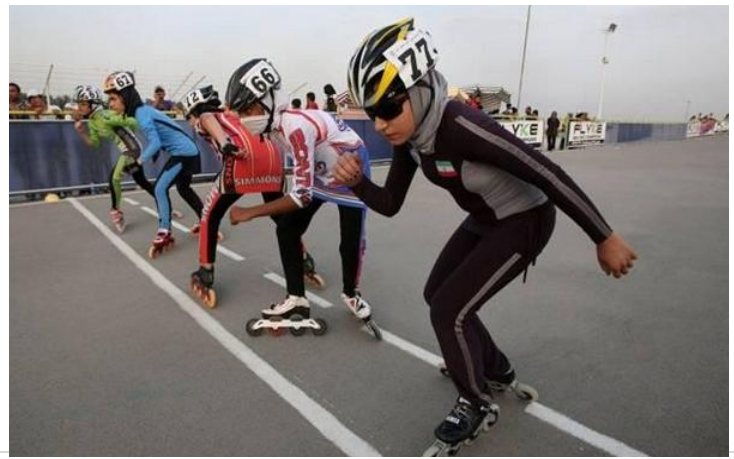

1060 | P a g e

April 2016 
In this photo, a group of girls are depicted who are involved in skates racing. Although the girls appeared with hijab (covering all their bodies), they wear tight clothing in the skating rink. In this photo, the photographer pointed to a change in Iranian society, he is trying to say that, today, women can participate in sport which were mostly male-driven a few years ago; they should still exercise the full hijab in public. But for Iranian society in which women have many limitations, this is considered a success. Therefore, according to Peirce's perspective, there is a causal relationship of indexical type in the picture. The social change among women in the society is the signifier (cause) and the signified (effect) is the women's participation in men's sport. The indexical relationship in this photo confirms the Burgin's critical perspective and because of the similarity of the photo with its object, an iconic relationship is also perceived. Based on the analysis, the results are given in tables and graphs below:

Table 1: different signs frequency in Reuters photos

\begin{tabular}{|c|c|c|}
\hline No. & Sign type & Frequency \\
\hline 1 & Iconic signs & 30 \\
\hline 2 & Indexical signs & 14 \\
\hline 3 & Symbolic signs & 10 \\
\hline
\end{tabular}

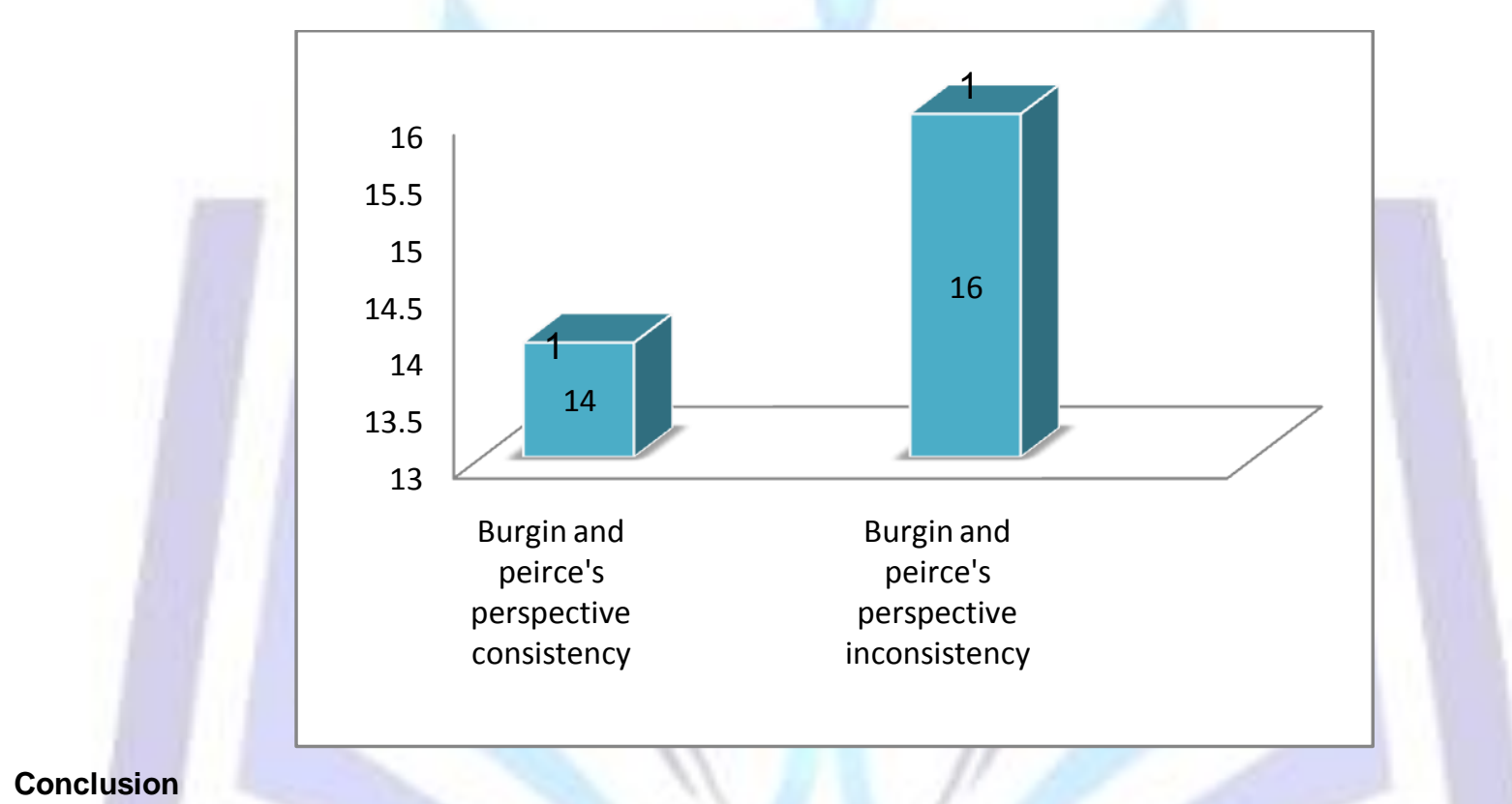

This article sought to comparatively examine different types of signs in Reuters news agency photos from Peirce and Burgin's perspectives. The results showed that most of the analyzed photos used cause and effect (signifier/signified) relationship, that is the indexical relationship, to convey meaning, because the photographer with a specific intention tried to show the social problems in Iran in his photos. So, the photographer tried to cast light on an issue through photos and related the reason to an issue in the society. Therefore, most of Reuters news agency photos are of signifier and signified (cause/effect) relationship type. Considering the iconic sign to have the highest frequency, the indexical relationship had the highest frequency. The findings also suggest that semiotic theories are used in photo interpretation. Each photo is a sign, a sign in the photographer's mind. Therefore, the photographer through using signs is trying to convey to the audience what he had in mind, so the theory of semiotics can be applied in photography. In addition, the semiotic study of Reuters social photo made it clear that photography has an arbitrary system. Considering the photographer's specific purpose to depict the pictures, the photographer considers a social issue, whether it is a normal or abnormal issue, then, he takes some pictures to portray the social issues in his photos to clearly offer it to the audience.

\section{REFRENCES}

1. Sojoodi, F. (2008). Applied semiotics, Tehran: Ghesse Publication.

2. Fokuhi, N. (2004). Urban Anthropology, Tehran: Ney publication.

3. Barthes, R. (1977). Image-Music-Text. London: Fontana.

4. Burgin, V. (1982). Editing Photography. London: ????

5. Duboa, N. (1983). Le processus interpretative, Introduction à la sémiotique de Ch. S. Peirce, Mardaga.

6. Maldonado, T. (1974). The Hidden Dimension, New York: Doubleday Anchor Books. 
7. Peirce, C. S. (1931). "Collected Papers", vol. 1-6, Cambridge (Massachusetts): Harvard University Press.

Biography of the first author: Foroogh Kazemi is assistant professor of linguistics department in Central Tehran Branch, Islamic Azad University in Iran. She has taught linguistics, Persian and English at Central Tehran Branch, Imam Khomeini International University and Science and Research branch. Dr. Kazemi has published many articles in linguistics and has been advisor, reader and referee of many linguistic MA theses and judge of articles in journal of linguistics. Her areas of interest are functional linguistics, sociolinguistics, typology and discourse analysis. She is the head of linguistics department and the head of research council in Central Tehran Branch, Islamic Azad University.

Biography of the second author: Narjes Ghasemi Ateni was born in Sari in 1983. She is BS of English Language Teaching at Sari Branch, Islamic Azad University, in 2008. She is now, MA student of linguistics, at Central Tehran Branch, Islamic Azad University. 